Document downloaded from:

http://hdl.handle.net/10251/112285

This paper must be cited as:

Miret Pastor, LG.; Molina-García, A.; García-Aranda, C.; Herrera-Racionero, P. (2018).

Analysis of the fisheries diversification funds in Spain during the period 2007 2014. Marine Policy. 93:150-158. doi:10.1016/j.marpol.2018.04.014

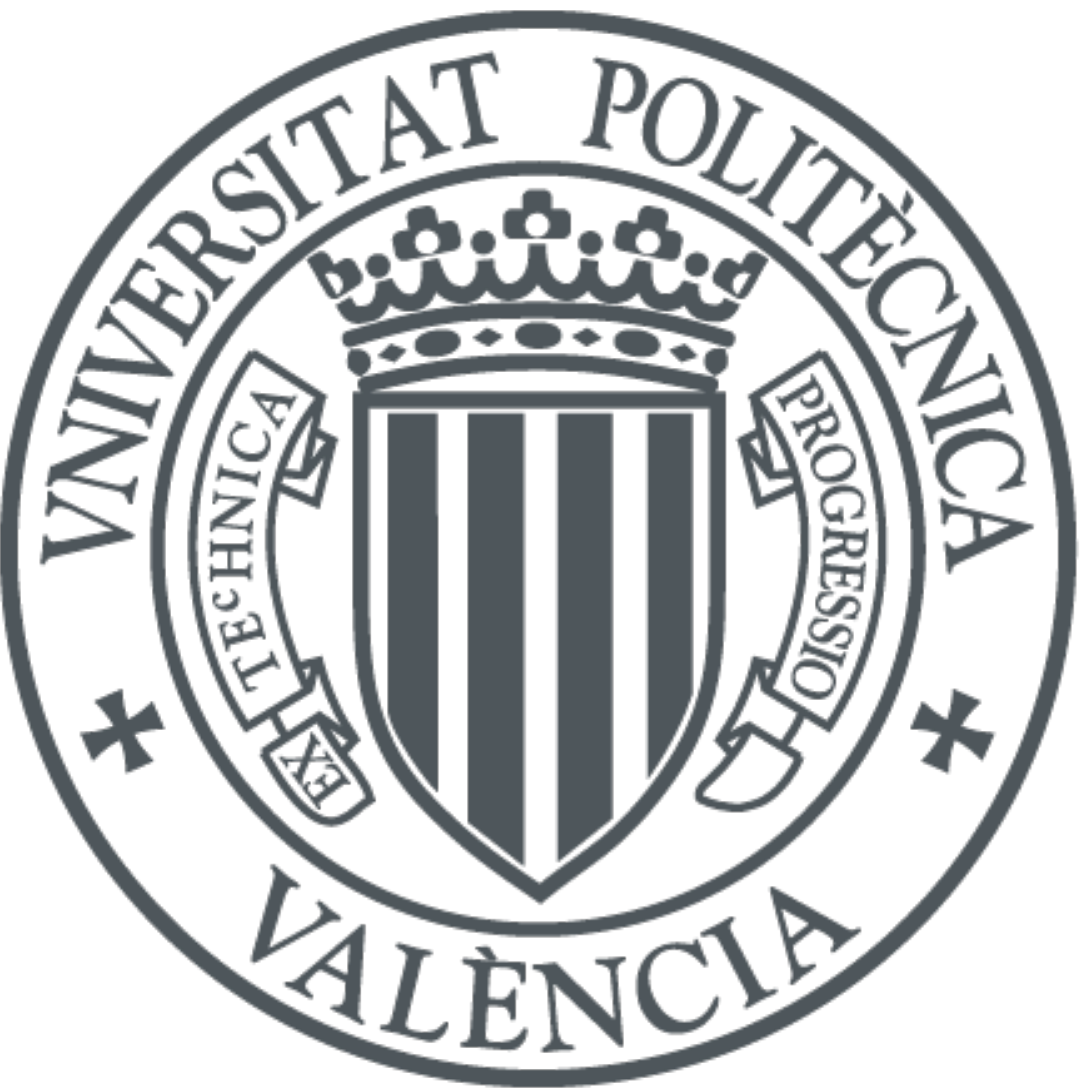

The final publication is available at

https://doi.org/10.1016/j.marpol.2018.04.014

Copyright Elsevier

Additional Information 


\title{
ANALYSIS OF THE FISHERIES DIVERSIFICATION FUNDS IN SPAIN DURING THE PERIOD 2007-2014
}

\author{
Lluís Miret Pastor. IGIC. Universitat Politècnica de València.
}

Agustín Molina-García. Universidad Politécnica de Madrid.

César García- Aranda. Universidad Politécnica de Madrid.

Paloma Herrera-Racionero. IGIC. Universitat Politècnica de València.

\begin{abstract}
A study has been carried out of the fisheries diversification projects in Spain during the period 2007-14, most of which were founded through Axis 4 of the European Fisheries Fund (EFF). On the one hand, the investments have been classified by areas of diversification in order to know how and where investment has been made and the quantities involved. On the other hand, the effectiveness of the different projects has been analysed from the point of view of the Fisheries Local Action Groups (FLAGs) managers. The results of this analysis may be useful for designing future diversification strategies in rural coastal areas, as well as for implementing similar strategies in other countries.
\end{abstract}

Key words: Fisheries diversification; fisheries policy; FLAGS; European Fisheries Fund. 


\section{1- Introduction}

The crisis in the fisheries sector and especially in small scale fisheries is causing serious social and economic problems in rural coastal areas dependent on fishing, with strong consequences on employment and quality of life (Lloret et al., 2016; MacFadyen, 2011; Maynou et al., 2013).

Although there are different causes for this crisis, Common Fisheries Policy (CFP) could have a hand in the matter (Symes, 2000; Phillipson and Salm, 2015). In fact, Symes (2000) argues that European Union (EU) policies are responsible for "many of the problems confronting fisheries dependent regions today", small scale fisheries have been neglected in Europe by fisheries scientists and management at national and supranational levels (Guyader et al., 2013; Guyader et al., 2007), which arises from an underestimation and under-appreciation of the social and economic value of its contribution to societal well-being, especially in rural coastal areas.

The EU itself is aware that the CFP may have significant negative impacts on fishing communities in the short term (European Commission, 2002), and to mitigate these effects is trying to diversify fisheries through the EFF.

This has led to an intense debate about the need to seek diversification alternatives (Gallizioli, 2015), which does not necessarily imply abandoning fishing and discarding the tradition and fishing identity of these communities. In fact, in recent years it is remarkable the efforts made by many fishing communities to achieve a more diversified economy that seeks alternatives to the primary sector without abandoning its fishing identity (Brookfield et al., 2005; Salmi, 2015) and its economic relationship with fisheries and the marine environment (Nielsen et al., 2014, Ross, 2013). Morgan et al. (2014) argue that diversification approaches are needed which complement and maintain a direct or 
indirect link to fishing, so that fishers can exploit their professional skills, knowledge and social networks gained through fishing (Symes, 2005).

Lately, there have been numerous fisheries diversification projects throughout Europe, most of them over the period 2007-2014 with funding from Axis 4 of the EFF. Many projects have focused on generating alternative sources of income for fishermen and their families, for instance to increase the value of fisheries products, as well as other sectors, as diverse as tourism, social services, arts and culture, renewable energies, information technology or environmental stewardship' (Budzich-Tabor, 2014).

Although the implementation of Axis 4 of the EFF through the Fisheries Local Action Groups (FLAGs) is relatively recent, there are already some studies evaluating their effectiveness in countries such as Greece (Loizou et al., 2014) or Finland (Godenhjelm, 2013). As well as on specific communities in France (Walle et al., 2015), Britain (White, 2015, Phillipson and Symes, 2015) or Italy (Marciano and Romeo, 2016).

This study analyses the fisheries diversification projects carried out in Spain during the period 2007-2014, and considers a double objective, on the one hand analysing the investments by areas of diversification, that is, to know how much has been invested and also how and where. This has led to a prior process of categorization of projects by modalities, areas and categories. On the other hand, the study determines the effectiveness of these projects from the managers' point of view (the FLAGs themselves). A questionnaire was designed with questions aimed at evaluating each area and category in terms of effectiveness for diversify, job creation and benefits brought to the sector, etc.

\section{2- Fisheries diversification and the European Fisheries Fund}

Within the framework of the Common Fisheries Policy (CFP), the European Fisheries 
Fund (EFF) introduces new mechanisms and accompanying measures for marine resources recovery plans and the financing of local strategies focused on the sustainable development of fishing areas. An overall budget for the period 2007-2013 of $4,304,949,019 €$ was earmarked for this purpose, Spain was the country with the highest assigned percentage of funding, $26.29 \%(1,131,890,912 €)$, in relation to the other countries of the European Union.

Axis 4 offered fishing communities a new opportunity for local territorial development and the improvement of quality of life by financing activities related to fisheries diversification.

The action guidelines for implementing the priorities financed by the EFF were set out in the Operational Programme of each Member State and, together with the National Strategic Plan, the priorities, objectives and public resources needed to achieve them were identified.

The Spanish Operational Programme of the EFF for the period 2007-2013, under Axis 4, included those activities aimed at stimulating the creation of new sources of sustainable income with an appreciable increase in the quality of life in communities and fishing areas. According to the regulatory framework, investment would go to specific territories and be implemented by Local Fisheries Action Groups (FLAGs). These groups are made up of representatives from the fisheries and aquaculture sectors, as well as including other members of the local community, who work together to design and implement a development strategy for their specific area. The composition of the FLAGs can vary from one area to another depending on the specific local conditions, being represented by the fishermen's associations, fishing producers' organizations, municipalities, universities, among other institutions. In Spain, 31 fishing groups were set up to be in 
charge of establishing the procedure for selecting and boosting projects in their area. The groups have to collect and analyse the documentation presented by each promoter, and decide on the suitability as well as on the technical, economic and financial feasibility of the presented project in accordance with the group's strategy. Based on these criteria, projects were selected for possible financing, channelled through the regional governments.

The Technical Working Group on Fisheries and Aquaculture Diversification (DIVERPES), created by the Ministry, was responsible for creating the strategic lines of diversification and entrepreneurship, in order to generate new sources of employment and income in fishing communities. In consensus with the regional governments, the National Strategic Plan defines key concepts such as "fishing diversification", "sailor tourism" or "fishing-tourism" and establishes four areas of action, considered the main drivers in fisheries and aquaculture diversification.

Diversification options:

- $\quad$ Tourism

- $\quad$ Processing and Marketing

- $\quad$ Environment

- Social 


\section{3- Methodology}

According to the first proposed objective, to analyse the investments by areas of diversification, first of all a form was designed to incorporate basic information: denomination of the project, description of the initiative, promoter, period of execution, budget and subsidy granted. The vast majority of these actions were projects funded through Axis 4 of the EFF, although information has been incorporated from other projects and diversification initiatives developed within the framework of other regional projects. In total, data was collected from a set of 705 projects with an investment amounting to $69,810,864 €$.

The classification process is as follows. Each one is first classified according to its productive or non-productive character. This distinction is purely administrative and is taken from the FARNET instructions (European Commission, 2010) which, in turn, derives from annex II of the Council Regulation EC 1198/2006 on the European Fisheries Fund (EC, 2006). This classification has been followed by various procedural manuals for EFF funding applications (Junta de Andalucía, 2011; Gobierno de Canarias, 2013; Xunta de Galicia, 2009). Secondly it is classified into one of the four areas as defined in the DIVERPES Strategic Plan (Tourism (TU), Processing and Marketing (TM), Environment (ENV) and Social (SC)). Finally, it is categorized into one of the multiple categories outlined in the tables below.

As a clarification, productive projects are considered to be those with a lucrative economic purpose, in which case the financing could reach a maximum of $60 \%$. While non-productive projects must be carried out by a public or private non-profit organization, and funding can reach $100 \%$ of the eligible costs of the project.

\section{Table 1 here}




\section{Table 2 here}

Based on this classification, it is intended, on one hand, to analyse in which categories investment is concentrated, as well as the average volume of investment. The identification of less-financed areas and categories will serve to rethink them or to explore the possibility of directing future efforts to some of these fields.

On the other hand, the comparative study between productive and non-productive projects will allow the analysis of the complementarity between private initiatives (basically productive projects) and the public non-profit initiatives (non-productive projects).

In relation to the second objective, to analyse the effectiveness of these projects from the managers point of view, the FLAGs managers were consulted to find their opinion regarding the adequacy of the diversification initiatives carried out in their territory and financed through Axis 4 of the EFF.

The consultation was carried out by sending a brief questionnaire that collected information on: 1) the area that more contributed to the diversification of the fishing sector; 2) the area that generated more employment; 3) the area in which greater coordination is necessary to enhance effectiveness and avoid overlaps; and 4) the different categories developed in each area with information on their degree of development, rating between 0 and 10 the benefit for the fishing sector and the benefit for other different sectors.

The questionnaire was sent by e-mail to the managers of the 31 fishing groups set up in the six Autonomous Communities that chose to use Axis 4 of the EFF (Catalonia, Galicia, Andalusia, Asturias, Canary Islands and Cantabria), together with a letter explaining the purpose and scope of the query. A satisfactory 24 responses were received with the completed questionnaire, within the deadline. Once the responses were tabulated and 
translated into empirical variables, the information was processed, using the IBM SPSS Statistics 20 software for data management and statistical analysis.

The statistical analysis consisted of a descriptive study of the data. Statistical tables (frequency distribution), statistical parameters (measures of centralization and dispersion) and their corresponding graphical representation were calculated. In addition, comparisons were made for each question among the different responses obtained.

With the statistical analysis carried out, it was concluded that there was a wide variability in responses, thus ruling out the possibility of taking the average to draw conclusions from the study, as results would be far removed from reality. This problem was solved by obtaining the median and the interquartile range, i.e. taking from the 25 th to the 75 th percentile, and focusing the study in this area, which allowed normalized indices for each response to be obtained.

Subsequently, from the index obtained for each item, comparisons were made between the categories and the average value per area. This identified the initiatives which obtained the highest and lowest values, as well as their relation to the average value of the area of diversification studied. Finally, for the graphical representation of this comparative analysis a scale of 0 to 10 was made, allowing for a better visualization of the results.

\section{4- Results}

\subsection{Analysis of investments by area of diversification}

In order to analyse investments by area of diversification, and based on the classifications set out above, the investment volumes and categories to which most of the investments are directed were identified. In most cases, a high percentage of investment it is concentrated in two, or at most, three categories. 
With respect to the volume of investment, it is necessary to point out that a certain action could be included by its objectives in more than one category of different areas. For this reason, mathematically, the sum of the investment volumes indicated in each area is slightly higher than the total investment made in all the projects analysed. Despite this accounting inaccuracy, it has been preferred to follow the criteria used in the classification of projects in order to reflect the investment in each area in a more appropriate way.

\section{Table 3 here}

In view of this data, it is significant to note that the two categories with the greatest volume of investment, both of which are in the tourism area, account for $44 \%$ of the total investment and account for $31 \%$ of the number of productive projects compiled in the whole of the Spanish coast. Expanding to the first six categories would result in more than $81 \%$ of the total investment and $75 \%$ of the projects developed.

\section{Figure 1 here}

It is clearly visible that investment declines markedly in the last categories, among which are those linked to the social and the environment areas. In fact, the investment made in the first six categories includes only initiatives within the areas of tourism and processing and marketing.

\section{Table 4 here}

It can be seen that the first four categories, which together account for $43 \%$ of total investments and for $35 \%$ of the number of non-productive projects, correspond only to initiatives within the social and environmental areas, contrary to what happens with productive projects. Extending to the ten categories with the highest investment volume, the total accumulated is $78 \%$ in investment and $71 \%$ in number of projects. 
Figure 2 here

It is evident, therefore, that investment in non-productive projects is mainly focused on the social area, towards initiatives related to raising awareness and training activities for the diversification of the fishing sector, largely carried out by the FLAGs themselves.

\subsection{The efficiency of investments according to the fishing sector}

Once identified where the diversification funds have been invested, the sector was asked about the impact of these investments, i.e. their effectiveness in terms of diversification, employment, benefits... To this end, the answers from the questionnaire are described in the "methodology" section.

The graphs represent, for each question, the average valuation obtained by each area of diversification. It should be noted that for the graphical representation and better interpretation of the results, the values obtained have been adjusted on a scale of 0 to 10 .

In relation to the first question regarding which area has more contributed to the diversification of the fishing sector, almost half of the respondents considered tourism as the one that contributed the most. The area of processing and marketing came second, followed by the environment and, finally, the social area.

Analysing the answers to the second question, which asked for their opinion on which area has generated more employment, it is observed that the valuations are reversed, being the area of processing and marketing considered to generate more jobs, followed by the tourism area. The environment and social areas are the least valued.

Finally, when asked which area would have required greater coordination between initiatives in order to enhance their effectiveness and avoid overlaps, the responses 
indicate the processing and marketing area, followed by the tourism and environment area. However, all three show little difference.

\section{Figure 3 here}

Regarding question 4, it was asked (with an assessment from 0 to 10) about each of the categories defined in the areas:

A. If the projects have been sufficiently developed in the area.

B. The degree of benefits that the projects have generated for the fishing sector.

C. The degree of benefits that the projects have generated in different sectors (other than the fishing sector).

Since the objective is to analyse the categories within each area, it has been chosen to show the results separately for each of the four areas of diversification.

\subsubsection{Tourism Area}

\section{Figure 4 here}

Regarding the question about the degree of benefits that tourism projects have generated for the fishing sector, the average value obtained was 6.29 out of 10 , while the average benefit of tourism projects in other sectors stands at 6.77. It is therefore curious to see how these projects are perceived to have an even greater benefit in other non-fisheries sectors, probably it can be assumed that these projects have mainly benefited sectors such as the hotel industry, restoration, retailers, etc. 
When analysing the results in relation to the degree of benefits provided by the projects, there is agreement that the Restoration and Gatronomic events, provide a clear benefit for both the fisheries sector and other sectors. There is also some coincidence in the degree of benefits from Tourism accommodation.

It is worth noting that Fishing tourism services are the least recognized. Probably the lower level of benefits perceived is due to the fact that this activity has not been developed in the coastal areas studied, with the exception of Catalonia (Molina-García and GarcíaAranda, 2013).

Analysing the answers to the question assessing whether the category has been sufficiently developed, found the average value for the Tourism Area to be 6.73 out of 10. These results show a direct relationship between the categories considered most beneficial and their degree of development, which is especially marked in Restauration and Gastronomic events.

However, other categories are also identified, such as Adaptation of infrastructures for tourism, and especially Marketing of fishing crafts that have been developed to a lesser degree, although they are classified as highly beneficial initiatives for the fishing sector.

\subsubsection{Processing and Marketing Area}

Figure 5 here

Analysing the responses regarding the degree of benefits for the fishing sector, the average values for each category and the mean value for the Processing and Marketing Area (7.07 out of 10) are shown. In terms of the perceived benefits to other sectors, in 
general the categories show values very close to the average value of the area, in this case of 6.49 out of 10 .

Contrasting both classifications, it is noted that investments concerning the Adequacy of facilities or infrastructure are considered highly valuable for all sectors, including fisheries. Similarly, investments in training and education, both Technical or sectorial seminars and Specific courses, are considered beneficial to all sectors. However, Equipment improvements are identified as a benefit primarily for the fishing sector, while Software for marketing and management is considered of more value for other sectors. This outcome could be interpreted as the fishing sector seeing itself more directly focused on the capture and processing phase of the product, while identifying other sectors with the marketing and distribution phase.

Finally, analysing the answers regarding whether the category has been sufficiently developed, the average value of the area was found to be 6.7 out of 10 . Interestingly, the first position is occupied by Specific courses, which contrasts with the question concerning project investment, in which this category does not appear as the main destination of investment, either in productive or non-productive projects. This could be explained by the high development of courses for the fisheries sector that are conducted outside Axis 4 of the EFF, in which case it would be interesting to further investigate if the current training plan responds to the needs of diversification activities.

On the other hand, there is a direct correspondence between Equipment Improvements and Adequacy of facilities and infrastructures and the volume of investment made, as well as the number of projects assigned to these categories.

\subsubsection{Environment Area}


Projects that improved environmental sustainability by avoiding accidental captures, by saving energy or by recycling generating waste, as well as projects related to the conservation and promotion of natural spaces in the fishing zones, have been included in the Environmental area. It must be pointed out here that some projects of an environmental character could be included in the Processing and Marketing area, such as investment in more efficient machinery or projects related to the use of sub products generated in processing activities.

\section{Figure 6 here}

In relation to the question regarding the degree of benefits for the fishing sector, the average value of the area is 6.51 out of 10 , while in the degree of benefits for other sectors, the average value of the area is 6.62 .

When comparing the results of both questions, it is observed that there is a coincidence in the most valued category Seminars and diffusion materials, posters, brochures, etc. so investment in this line is considered to have a positive effect on both the fisheries sector and other sectors.

Finally, analysing the answers regarding whether the categories of the Environment Area have been sufficiently developed in the area, the average value is 6.5 out of 10 .

According to the assessment, and in contrast to the categories that have received the greatest investment in projects, the conclusion can be drawn that non-productive investment seems to have largely covered the needs related to the promotion and diffusion of environmental values. It is noteworthy that, according to the opinion of the respondents, Interpretation centres or nature classrooms seem to have a high development potential in the areas studied. 


\subsubsection{Social Area}

It must be pointed out that the Social area includes projects which promote equal opportunities, incorporation of disadvantaged groups into the employment market, improvement of the quality of life in coastal zones or training activities. Also included are any activities which offer a service to the community (cultural and leisure centers, retirement homes, etc). In practice the more difficult projects to classify have been included in this area, for example projects aimed at youth inclusion, training for the selfemployed, IT training, social centre improvements or FLAGs promotional activities.

\section{Figure 7 here}

Analysing the responses on the degree of benefits generated in the fishing sector, the average value for Social Area is 6.7 out of 10, while the degree of benefits generated in other sectors gives a value of 6.61 .

Comparing both results, it is possible that in the Social Area, due to the diversity of projects and their broad purposes, the benefits of these are perceived as a global benefit for the region or territory, without identifying marked differences between the fishing sector and the other sectors that both favour local development.

Finally, analysing the answers about whether the categories have been sufficiently developed in the area, an average of 6.75 out of 10 is obtained.

According to the results, it can be concluded that the categories considered to be of greatest benefit to the fishing sector, and also to other sectors, are those that have developed to a greater degree.

\section{5- Discussion.}


This section contrasts the results of the analysis of investment by areas of diversification versus the perception of the sector regarding the effectiveness of investment, highlighting the most significant aspects identified.

From the analysis of the investment categorization and the opinion of those responsible for the FLAGs, tourism has been consolidated as the main line of diversification in the period analysed, having accumulated more than half of the total volume of investment analysed, both in productive and non-productive projects.

Among the productive projects of the Tourism Area, the three most developed categories have concentrated more than $80 \%$ of the total investment and have focused on tourist accommodation and Restoration. Together they have accumulated an investment of more than ten million euros, developed through 65 projects. Although the accumulated investment in restoration is similar to that made in Tourist accommodation, the average number of projects in this last category doubles that of Restoration.

To a lesser extent, a total of 37 productive projects have also been developed for Nautical tourism, diving and tourism, which have accumulated a total investment of more than five million euros.

The opinion of the FLAGs managers confirm that these activities have been sufficiently developed and they has been consolidated, mainly Restoration, as the activities most beneficial for the fishing sector as for other sectors of the local economies.

Within the Processing and Marketing Area, another great category that has accumulated a significant part of the investment in productive projects has been the Equipment improvement, together with the Adequacy offacilities and infrastructures, which together totals 70 projects and nearly seven million euros of investment. With average allocations per project being higher than the investment in Restoration, they respond to the 
prioritization manifested by the FLAGs in terms of the degree of benefits for the fishing sector.

Both the Environment Area and the Social Area have had little development in productive diversification activities. This is in line with the opinion of the FLAGs, who consider that the activities carried out in these areas come under non-productive projects.

In the Social Area, the category that has received a greater volume of investment is Other infrastructures and services, which, as already mentioned, includes projects that are difficult to classify in the other categories. Investment in more innovative lines such as the development of Aquaculture facilities and equipment, algae extraction, corals has been much less, although in some cases it has been developed thanks to specific projects with high investment levels.

Likewise, the investments of a productive nature related to the Environment Area have been very small, possibly because they are less known and exploited and above all because they are not considered as an alternative or complement to the fishing activities in the coastal zones.

It is evident therefore that the investment in non-productive projects is mainly focused on the Social Area, highlighting the initiatives related to Training or dissemination activities for the fishing sector, and the Adaptation of social infrastructures (mainly in fishermen's guilds), largely carried out by the FLAGs themselves, with a cumulative investment of slightly more than five million euros and a total of 55 projects. Both lines of action are those that the FLAGs consider to provide a greater benefit for all sectors, including the fishing industry.

The other priority in non-productive projects has been directed towards the Environment Area, mainly in actions for the dissemination and improvement of the coastal natural 
environment and its resources, including fishing, through the creation of interpretation centres and environmental improvement actions in ports, markets and coastal areas. Altogether these have involved investment of six and a half million euros and a total of 52 projects. Based on the opinions gathered, the FLAGs clearly agree that the initiatives that have generated the greatest benefit have been awareness-raising actions through workshops, as well as the implementation of interpretation centres and nature classrooms, although the latter is not considered to have been sufficiently developed in the period analysed.

On the other hand, the analysis confirms that the categories of non-productive projects with the greatest investment in the Tourism Area do not coincide with the most developed productive categories, but respond to investments related to the improvement of tourism promotion. This is achieved through the establishment of tourist routes, the design of web applications or through the adaptation for visits to fishing facilities and the organization of gastronomic events.

The evidence of this complementarity is clearly reflected in the analysis of the FLAGs opinion regarding the assessment of the degree of benefits provided by the Tourism Area categories. There is unanimity in giving the highest valuation, clearly above the average value of the area, both to the Restoration and to the Gastronomic events, the latter being non-productive activities that complement and support the productive investments in Restoration or even Tourist accommodation. It should be noted that both categories have had the greatest number of projects developed.

The Processing and Marketing Area is the one that has generated the smallest nonproductive investment (only $12 \%$ of the total initiatives) with actions mainly directed to the Adequacy of facilities and infrastructures. However, it is worth noting that, in agreement with the opinion of the FLAGs, the development of projects aimed at the Pilot 
testing, traceability studies, labelling and product lines, is presented as a line of special interest for future projects.

\section{6- Conclusions}

This study shows that fisheries and aquaculture diversification activities provide important support for maintaining employment and quality of life in coastal areas dependent on fishing. The majority of FLAG leaders are aware of their potential contribution to the social and economic development of the fishing sector, mainly those activities linked to tourism and processing and marketing.

One of the main conclusions to be drawn is that there is a clear dichotomy between productive and non-productive projects. Productive projects are confined to only a few activities (especially tourism, but also to marketing), with no significant quantitative relevance to environmental or social projects. It should be borne in mind that productive projects are usually based on private initiatives, while non-productive projects tend to have a public non-profit nature. Therefore, one of the conclusions is that the promotion of productive investment projects in the environmental and social areas must be worked on, since their potential has yet to be realised by the private sector. In fact, the FLAG managers themselves see the environmental and social areas as less important for job creation and diversification. In Spanish coastal areas, wealth and employment are rapidly identified with tourism. Legislative and social changes could alter this in coming years. Social and environmental issues related to fisheries must play a fundamental role and become an important source of wealth and employment. In our opinion, future diversification policies should follow this line.

In any case, this analysis has allowed for the identification of future lines of investment that, according to the sector, should be a priority in future calls for diversification (such 
as "development of projects aimed at labelling, traceability and branding of fishery products").

Another of the conclusions reached is the need to coordinate more and better nonproductive activities with productive ones. It is assumed that the non-productive projects must serve as support and promotion to the productive ones. There must be a complementarity between both, however, in practice, does not happen at all. There is a certain degree of logic for the different investment made by private and public agents, which is not unreasonable, but work must be done on improving coordination and complementarity between both. An example of this complementarity is clearly reflected in the valuation of the gastronomic days and the promotion of fishery products, both being non-productive activities that complement and support the productive investments of restoration and valuation of fishery products.

Since much of the investment in fishery diversification goes to tourism activities, it is important to highlight an issue that does not appear in the study, but which is of vital importance: "who" is receiving these funds. Considering the Sea Fisheries Act, diversification activities of fishing and aquaculture must be conducted by professionals in the fisheries sector and be complementary to fishing activities. However, the law does not establish what activities are considered complementary to fishing activities. Moreover, the issue becomes more complicated when it comes to activities carried out by relatives of the professionals. Consequently, in order to be able to delimit conceptually the diversification of fisheries, it would be desirable to establish the activities considered complementary to the fishing activity, in a similar way to agricultural activity in Spain.

In our opinion, this type of work is fundamental to seeking a more rational use of public resources. It is necessary to improve the effectiveness of fisheries policies for the social 
and economic development of the fisheries sector. Diversification strategies should be based on the generation of synergies between them and traditional fishing activities. Diversification activities will be more viable if they share both tangible resources (vessels, port facilities, etc.) and intangible resources (knowledge of the marine environment, culture, etc.) with fishing or aquaculture. For this purpose, the analysis of investments can be used to analyse the traction and complementarity of different diversification activities, as well as to gain a better understanding of economies of scope or range in the diversification processes.

In any case, methodologies that allow the evaluation of public policies should be improved. The objective of this work has been to take this line, although it is still necessary to identify new ways of analysing the effectiveness of these investments (either through other qualitative methods involving other stakeholders or through quantitative methods), as well as finding ways to analyse the level of efficiency.

The conclusions will hopefully help to evaluate the fisheries diversification policies carried out so far in Spain, which will lead to improvements for future calls for fishing diversification and help the implementation of more effective policies throughout the European Union.

\section{Funding}

The authors would like to thank the Spanish Economy and Competitiveness Ministry for its support through the Research Project CSO2016-76135-P.

\section{References}


Brookfield, K., Gray, T., \& Hatchard, J. (2005). The concept of fisheries-dependent communities: a comparative analysis of four UK case studies: Shetland, Peterhead, North Shields and Lowestoft. Fisheries Research, 72(1), 55-69.

Budzich-Tabor, U. (2014). Area-based local development - a new opportunity for European fisheries areas. Pp. 183-197 in J. Urquhart, T.G. Acott, D. Symes et al. eds, Social issues in sustainable fisheries management. MARE Publication Series (9) (New York, London: Springer, Dordrecht Heidelberg).

Commission of the European Communities, (2002). Communication from the Commission on the Reform of the Common Fisheries Policy (Roadmap). COM (2002) 181 final, Brussels.

EC (2006). Council Regulation (EC) No 1198/2006 of 27 July 2006 on the European Fisheries Fund.

https://eur-lex.europa.eu/legalcontent/EN/TXT/HTML/?uri=LEGISSUM:166004\&from=ES

European Commission (2010): FARNET Guide 2. Working together for EU fisheries areas. Pp. 7-8

https://webgate.ec.europa.eu/fpfis/cms/farnet/sites/default/files/documents/FARNET\%2 0Cooperation\%20Guide\%20EN.pdf

Gallizioli, G. (2014). The social dimensions of the Common Fisheries Policy: a review of current Measures. Pp. 65-78 Pp. in J. Urquhart, T.G. Acott, D. Symes et al. eds, Social issues in sustainable fisheries management. MARE Publication Series (9) (New York, London: Springer, Dordrecht Heidelberg). 
Gobierno de Canarias (2013): Orden de 7 de junio de 2013, por la que se convocan para el ejercicio 2013 las subvenciones destinadas a financiar los proyectos que se adecúen a los criterios fijados en los Planes Estratégicos Zonales de los Grupos de Acción Costera en el marco del Eje 4. Boletín Oficial de Canarias (BOP) $N^{o} 116$. http://www.gobiernodecanarias.org/boc/2013/116/002.html

Godenhjelm, S. (2013). Project impact in a multi-level context: The case of the European Fisheries Fund evaluation in Finland. Scandinavian Journal of Public Administration, 17(2), 79-101.

Guyader, O., Berthou, P., Koustikopoulos, C., Alban, F., Demaneche, S., Gaspar, M., Eschbaum, R., Fahy, E., Tully, O., Reynal, L., Albert, A. (2007). Small-Scale Coastal Fisheries in Europe, Final report of the contract No FISH/2005/10, http://ec.europa.eu/fisheries/publications/studies reports en.htm

Guyader, O., Berthou, P., Koutsikopoulos, C., Alban, F., Demaneche, S., Gaspar, M. B., Eschbaum, E. Fahy, O. Tully, L., Reynal, L., Curtil, O., Frangoudes, K (2013). Small scale fisheries in Europe: A comparative analysis based on a selection of case studies. Fisheries Research, 140, 1-13.

Junta de Andalucía (2011): Guía de Procedimientos de Gestión y Control del Fondo Europeo de Pesca.

http://www.juntadeandalucia.es/agriculturaypesca/portal/export/sites/default/comun/gale rias/galeriaDescargas/cap/pesca-yacuicultura/FEP/GUIA_PROCEDIMIENTOS_FEP_xV2x_xabril11x.pdf Lloret, J., Cowx, I. G., Cabral, H., Castro, M., Font, T., Gonçalves, J. M., ... \& MoralesNin, B. (2016). Small-scale coastal fisheries in European Seas are not what they were: Ecological, social and economic changes. Marine Policy. 
Loizou, E., Chatzitheodoridis, F., Polymeros, K., Michailidis, A., \& Mattas, K. (2014). Sustainable development of rural coastal areas: Impacts of a new fisheries policy. Land Use Policy, 38, 41-47.

MacFadyen, J.G., Salz, P., Cappell, R. (2011). Characteristics of small-scale coastal fisheries in Europe. Brussels: European Parliament's Committee on Committee on Fisheries.

http://www.europarl.europa.eu/RegData/etudes/etudes/join/2011/460059/IPOLPECH_ET(2011)460059_EN.pdf

Marcianò, C., \& Romeo, G. (2016). Integrated Local Development in Coastal Areas: The Case of the "Stretto" Coast FLAG in Southern Italy. Procedia-Social and Behavioral Sciences, 223, 379-385.

Maynou, F., Morales-Nin, B., Cabanellas-Reboredo, M., Palmer, M., García, E., \& Grau, A. M. (2013). Small-scale fishery in the Balearic Islands (W Mediterranean): a socioeconomic approach. Fisheries research, 139, 11-17.

Molina-García, A., García-Aranda, C., (2013). Diagnóstico estratégico de la actividad de Pesca-turismo en España. Secretaría General de Pesca del Ministerio de Agricultura, Alimentación y Medio Ambiente.

Morgan, R., M. Lesueur and L.-M. Henichart. (2014). Fisheries diversification: a case study of French and English fishers in the Channel. Pp. 165-182 in J. Urquhart, T.G. Acott, D. Symes et al. eds, Social issues in sustainable fisheries management. MARE Publication Series (9) (New York, London: Springer, Dordrecht Heidelberg).

Nielsen, A.L., R. Gabriel, A.M. Arroz et al. (2014). Perspectives about the sea in the Azores: respecting narratives that sustain inshore fishing communities. Pp. 319-338 in J. Urquhart, T.G. Acott, D. Symes et al. eds, Social issues in sustainable fisheries 
management. MARE Publication Series (9) (New York, London: Springer, Dordrecht Heidelberg).

Phillipson, J., \& Symes, D. (2015). Finding a middle way to develop Europe's fisheries dependent areas: the role of fisheries local action groups. Sociologia Ruralis, 55(3), 343359.

Ross, N. (2013). Exploring concepts of fisheries 'dependency' and 'community' in Scotland. Marine Policy, 37, 55-61.

Salmi, P. (2015). Constraints and Opportunities for Small-Scale fishing livehoods in a Post-Productivist Coastal setting. Sociologia Ruralis, 55(3), 258-274.

Symes, D. (2000). Fisheries dependent regions: scoping the problem. In: Symes, D. (Ed.), Fisheries Dependent Regions. Blackwell Science, Oxford.

Symes, D. (2005). The future for fishing dependent areas. Paper presented at Prospects for the Development of the Fisheries Sector 2007-2013, 15-16 April, 2005, Athens.

Symes, D., Phillipson, J. and Salmi, P. (2015). Europe's coastal fisheries: instability and the impacts of fisheries policy. Sociologia Ruralis. In Press.

Walle, G., Gomes da Silva, S., O'Hara, E., \& Soto, P. (2015). Achieving sustainable development of local fishing interests: the case of Pays d'Auray FLAG. Sociologia Ruralis, 55(3), 360-377.

White, C. S. (2015). Getting into fishing: recruitment and social resilience in north Norfolk's ‘Cromer crab’fishery, UK. Sociologia Ruralis, 55(3), 291-308.

Xunta de Galicia (2009): Orde do 27 de agosto de 2009 pola que se establecen as bases reguladoras para a concesión de axudas para proxectos ao abeiro dos plans estratéxicos zonais aprobados pola Consellería do Mar aos grupos de acción costeira, e se procede á convocatoria 
para o ano 2009. http://www.accioncosteira.es/archivos/Orde\%2027-8-09bases\%20axudas\%20pez.pdf 